\title{
Albert MATHIEZ, La Réaction thermidorienne
}

\section{Christine Le Bozec}

\section{(2) OpenEdition \\ Journals}

\section{Édition électronique}

URL : https://journals.openedition.org/ahrf/12188

DOI : 10.4000/ahrf.12188

ISSN : 1952-403X

\section{Éditeur :}

Armand Colin, Société des études robespierristes

\section{Édition imprimée}

Date de publication : 1 septembre 2011

Pagination : 225-226

ISBN : 978-2-200-92700-4

ISSN : 0003-4436

\section{Référence électronique}

Christine Le Bozec, «Albert mathiez, La Réaction thermidorienne », Annales historiques de la Révolution française [En ligne], 365 | Juillet-septembre 2011, mis en ligne le 13 décembre 2011, consulté le 23 avril 2022. URL : http://journals.openedition.org/ahrf/12188 ; DOI : https://doi.org/10.4000/ahrf.12188

Ce document a été généré automatiquement le 23 avril 2022.

Tous droits réservés 


\title{
Albert MATHIEZ, La Réaction thermidorienne
}

\author{
Christine Le Bozec
}

\section{RÉFÉRENCE}

Albert MATHIEZ, La Réaction thermidorienne, présentation Yannick BOSC et Florence

GAUTHIER, Paris, La Fabrique éditions, 2010, 410 p., ISBN 978-2-35872-012-0, $25 €$.

1 La Fabrique éditions vient de rééditer La Réaction thermidorienne d'Albert Mathiez. Cet ouvrage fut publié chez Armand Colin, en 1929, trois années avant que son auteur ne meure, devant ses étudiants pendant le cours qu'il dispensait, le 25 février 1932, à la Sorbonne dans l'amphithéâtre Michelet. Ce volume fait suite aux trois tomes de La Révolution française $(1922,1924,1927)$

2 Ce travail fondateur - il a aujourd'hui plus de 80 ans - est divisé en 12 chapitres, consacrés à 12 séquences qui constituent un parcours canonique des travaux sur la Convention thermidorienne, pour aller vite, sur l'an III. Cet ouvrage, désormais patrimonial, marque un moment historique et historiographique important quant aux nombreuses pistes qu'il a ouvertes aux générations de chercheurs qui lui ont succédé. Il a joué un réel rôle d'éclaireur.

3 Ces 12 séquences nous conduisent du démantèlement du gouvernement révolutionnaire à Vendémiaire en passant par le procès Carrier, la fermeture du Club des Jacobins, la Jeunesse dorée, le rappel des Girondins, l'amnistie aux Vendéens et aux Chouans, Quiberon, la Terreur blanche, les journées de Germinal et Prairial la rédaction de la Constitution de l'an III, le rôle joué par des " politiques » comme Tallien, Fréron, Babeuf, entre autres. Il y a constamment aller-retour entre les institutions, les hommes et les circonstances, complété par des références aux archives et travaux consultés.

4 Les travaux de Mathiez ont constitué une entreprise de réhabilitation de Robespierre et du jacobinisme. Et là, avec La Réaction thermidorienne, il analyse avant leur effondrement total, en tant que groupe politique, leurs querelles, leurs lâchetés, leurs peurs, leurs 
mesquineries, leurs reniements, leurs contradictions exacerbées par le fait que l'opinion ne les suit plus, ces Jacobins. Elle s'est détournée, déçue, lasse et aussi travaillée par une presse anti-jacobine efficace. Ils sont dépassés, s'entre-déchirent et n'ont plus qu'une préoccupation, non pas sauver la république mais se sauver euxmêmes. Certains en prennent conscience, d'autres se ressaisissent, mais il est tard, ils ne sont plus très nombreux, représentés par la Crête puis symbolisés par les martyrs de Prairial. Mathiez, devant ce recul, cet affaiblissement puis cette disparition, y voit la hargne vengeresse des Dantonistes. Cela revient en boucle, tout au long des séquences, le retour et la volonté de vengeance de ceux-ci. Pour lui, la réaction thermidorienne signifie d'abord un retour en arrière et ce, avant la mise en place d'une vie politique nouvelle avec éviction des masses, maintien en respect du royalisme et installation d'une future classe politique puis d'une notabilité en devenir. Des élus politiques qui se sauvent, non plus en tant que détenteurs d'une partie de la souveraineté nationale dont ils seraient les représentants et les garants mais des politiciens devenus des professionnels de la politique et dont les intérêts personnels sont communs.

mutandis, l'analyse faite par Albert Mathiez de ce moment de l'an III nous renvoie un large et troublant écho de notre expérience contemporaine. Il y étudie la primauté des intérêts particuliers, les illusions du libéralisme économique, le règne de la finance, l'étalement provocant des richesses et d'un luxe insolent, la primauté des " amis », la cohésion du groupe dirigeant, l'impunité des coquins, l'appauvrissement généralisé des populations, la perte de confiance dans les dirigeants politiques, le désespoir, et le dégoût caractérisant la population déçue.

6 Quant à la présentation de cette réédition, si l'on considère l'importance de cet ouvrage, l'originalité du travail et les pistes ouvertes, elle peut sembler réductrice. Car faire d'Albert Mathiez d'abord et avant tout le héraut de la lutte antistalinienne, la cible des staliniens, semble un peu court. Un seul exemple, celui des 19 occurrences, «Staline », « stalinisme », « stalinien(ne) » en 37 pages, qui pourrait prêter à confusion et donner le sentiment que son travail s'est résumé à condamner Staline, le stalinisme et les staliniens et à être vilipendé par ces derniers ! Même si Mathiez fut à un moment attaqué pour avoir quitté le Parti communiste Français et accusé d'avoir rejoint le clan social-démocrate, ce n'est guère la ligne directrice de cette étude.

7 Cette insistance, un peu réchauffée, risquerait de masquer ou d'occulter la richesse et le foisonnement d'un ouvrage fondateur que cette réédition met désormais à la portée de tous. Et c'est bien là l'essentiel. 